\title{
Laura Pasquali (Directora). Mujeres y política en escenarios de con- flicto del siglo XX. Rosario: ISHIR-CONICET, 2016, 205 páginas.
}

\author{
María Eugenia Sánchez ${ }^{1}$
}

$\mathrm{L}$

a historiografía de las últimas tres décadas ha incorporado a las mujeres como sujetos históricos desde una perspectiva que en parte se nutre de los aportes realizados por la crítica feminista reiniciada en los años ' 70 y que continuó con una diversidad extraordinaria desde entonces. Así, desde la historia política se revisaron períodos y problemáticas bajo el supuesto de que las relaciones entre los géneros implican relaciones de poder y, por lo tanto, se trata de vínculos históricos. Esta inclusión supone repensar metodologías de trabajo y fuentes de consulta, ya que nos enfrentamos al estudio de un sujeto olvidado por la historia y que no se encuentra presente de la misma forma que los hombres en las fuentes tradicionalmente consultadas. El libro dirigido por Laura Pasquali realiza un aporte en este sentido; muestra el potencial de la historia oral como metodología cualitativa para el estudio de las mujeres en el campo de la renovada historia política, en este caso de la militancia femenina y su utilización para períodos previos a la historia reciente, época en la que es aplicada.

Este volumen se presenta como una compilación de seis entrevistas realizadas por seis investigadoras- a mujeres de la ciudad de Rosario (provincia de Santa Fe, Argentina) durante diferentes momentos del siglo XX. El hilo conductor que las atraviesa es el de los cambios producidos en la subjetividad femenina de mujeres que militaron en organizaciones políticas y de derechos humanos durante distintos procesos históricos. Cada una de ellas aporta información y reflexiones particulares, así contribuye a percibir diferencias y matices en sus experiencias debido a las singularidades de cada contexto histórico, de la ubicación socioeconómica, generacional y la filiación política de cada una. Los relatos se presentan como la principal y, en algunos casos, la única fuente de consulta de los artículos que componen la obra.

Pasquali señala que el objetivo de la compilación es traspasar los

\footnotetext{
1 Centro de Investigaciones-Facultad de Filosofía y Humanidades-Universidad Nacional de Córdoba. Argentina. Correo electrónico: meugesanchez@gmail.com
} 
aspectos políticos de las biografías y desde la historia oral es posible lograrlo. Además, sostiene que el relato en primera persona de vivencias personales lleva a realizar construcciones más complejas que involucran otras dimensiones de análisis más allá de las tradicionalmente usadas por los historiadores, tales como memoria y sentimientos de los narradores. Sin lugar a dudas, la historia oral puede realizar importantes contribuciones a la historia de las mujeres, más aún en terrenos poco explorados por la historiografía como es el de la militancia femenina. Sin embargo, requiere de la destreza del investigador para contextualizar y problematizar lo relatado, tarea que a lo largo de la obra se logra en algunas oportunidades mientras que en otras el lector se queda con la necesidad de contar con mayores respuestas.

Las transcripciones de los testimonios se distribuyen en cuatro capítulos. A cada relato le antecede una breve descripción del contexto político general y una concisa biografía de la entrevistada. Los apartados se disponen cronológicamente, de esta manera el lector recorre distintas experiencias de militancia femenina que comienzan en la década del '30 y terminan en la del '90. De allí la diversidad de los temas analizados: la participación en organizaciones antifascistas y en el comunismo; la militancia estudiantil y la guerrilla; las organizaciones de derechos humanos de madres y abuelas de desaparecidos, para terminar con la experiencia de una mujer en el campo universitario y científico en los años '90. El eje que atraviesa estas pesquisas evidencia cómo a lo largo de las experiencias de lucha, estas mujeres, tanto en ámbitos sindicales como partidarios, fueron moldeando socialmente y estableciendo vínculos de poder disímiles a los que la cultura patriarcal quería atribuirles. Si bien la organización de la presentación sigue un criterio diacrónico, la riqueza del testimonio hace que se Ileguen a percibir sincronías, continuidades y particularidades. Los relatos exceden las periodizaciones de cada capítulo, como a las presentaciones realizadas por las autoras.

En el primer capítulo, Laura Pasquali rescata a las mujeres en su militancia antifascista y sindical en Rosario durante las décadas de 1930 y 1940, a partir del testimonio de Amor Alba Fernández, quien se incorporó tempranamente al Partido Comunista y llegó a ser delegada sindical ante la Federación Obrera de la Industria del Vestido, además de participar en la Unión de Mujeres de la Argentina -UMA-. La biografía de Amor es un ejemplo de la continuidad de las tradiciones políticas de todo el siglo XX. Permite observar las transformaciones que produjo su militancia a lo largo de los años, desde la experiencia de lucha en el plano sindical y partidario hasta en las organizaciones de mujeres. Si bien la autora circunscribe el tema del capítulo en el período 1930-1940, los recuerdos de Amor se extienden hasta los tiempos peronistas y los años setenta. 
De esta manera, este relato posibilita contraponer y enlazar su experiencia con las de las otras entrevistadas que presenta el volumen. Lo cual incentiva en el lector el surgimiento de interrogantes acerca de las posibles relaciones entre militancia y diversas generaciones.

El segundo apartado aborda la participación de las mujeres en la guerrilla durante los años '70. Las investigadoras Nadia Freytes y Paola Martínez indagan en los momentos de quiebre y de reformulación de los roles de género que la sociedad asignaba a las mujeres a partir del testimonio de dos militantes: Gloria Conteloro de la Unión de Estudiantes Secundarios y, posteriormente, de la Juventud Peronista; y Nelfa Suárez del Partido Revolucionario de los Trabajadores-Ejército Revolucionario del Pueblo. Las autoras recuperan el lugar asignado a las mujeres en ambas organizaciones, de signo absolutamente opuesto para los contemporáneos. Señalan que a pesar de las diferencias de género respecto a la distribución de tareas, éstas tuvieron un desempeño importante como militantes, lo cual contribuyó decididamente a que la sociedad diera otros sentidos a los roles femeninos, no solo el asociado a la maternidad. Ambas entrevistadas mencionan que las diferencias entre hombres y mujeres al interior de estas agrupaciones se reflejaba en que muy pocas mujeres llegaban a formar parte de la conducción, no obstante el anhelo de las militantes por alcanzar la igualdad con los varones. Por esta razón, cuestionaban la reproducción dentro de sus organizaciones políticas de los roles tradicionales que la sociedad le adjudicaba a las mujeres, máxime cuando la conducción les asignaban solo el cuidado de los niños u otras tareas del hogar. Además, se observa la resignificación de la maternidad realizada por la militancia. Las concebían como madres militantes que daban hijos a la Patria, aspiraban a transformarles el mundo en el que vivirían mediante su activismo y a educarlos para la revolución; situaciones que ya habían sucedido con muchas mujeres en diversos países, estimuladas por diferentes ideologías estatistas. Entonces, el sentido de ser mujer se ligaba a la maternidad ya no desde su acepción tradicional, sino vinculada a un rol político, el que excedía el ámbito del hogar.

El capítulo siguiente pone nuevamente de manifiesto la resignificación de la maternidad, al estudiar las trayectorias y las transformaciones de la subjetividad femenina realizada en organizaciones de derechos humanos al iniciar la búsqueda de sus hijos y nietos desaparecidos por el accionar del terrorismo de Estado en Argentina. Así, Marianela Scocco y Pamela Gerosa se interesan por la socialización de la maternidad a partir de los testimonios de la experiencia personal de Esperanza Labrador -fundadora de la delegación Rosario de Madres de Plaza de Mayo- y de Delia Cecilia Giovanola -fundadora de Abuelas de Plaza de Mayo en esa misma ciudad-. Las autoras señalan 
la invención de una subjetividad que crea una forma específica de lenguaje y de experimentación de la política. El inicio de la militancia de estas mujeres estuvo signado por la emocionalidad básica de un ser humano: la desaparición de un hijo y, en el caso de Delia, también la de su nieto. De allí que su búsqueda las impulsó de una u otra forma a salir a la arena política sin importarles qué arriesgaban con su nueva acción ante un Estado criminal. En este caso se observa cómo la maternidad devino en una construcción colectiva para estas mujeres ocupadas en luchar contra la violación de los derechos humanos, ya no como una condición biológica y natural. Es el único apartado que estudia a militantes que no iniciaron el activismo político durante su juventud, lo cual abre nuevamente interrogantes interesantes sobre la relación entre militancia y diferencias generacionales. Cuestiones que, sin embargo, no son problematizadas por las autoras.

Por último, Gisela Figueroa indaga a las mujeres que trabajan en el campo científico y universitario. Contextualiza la entrevista a Liliana Gómez -física, investigadora del CONICET y docente universitaria-, insertándola en la problemática de la ciencia y la universidad en Argentina durante los años '90 desde una perspectiva de género. Este testimonio se enlaza con los anteriores, dado que su trayectoria como científica se ve atravesada por su militancia en los años '70. La autora presenta, mediante datos cuantitativos obtenidos del CONICET, el lugar de la mujer en la ciencia argentina; luego, a partir del relato de Gómez, es posible reconocer las disposiciones de raigambre patriarcal en esos espacios que obstaculizan el avance de las mujeres en la carrera científica. No obstante, la entrevistada sostiene que en su caso experimentó mayor discriminación por su pasado de ex presa política que por su condición de mujer y madre, aunque igualmente estos fueron condicionantes en su trayectoria profesional. Esta situación la impulsó a generar estrategias para proseguir y lograr estabilidad en su trabajo, conjugando su profesión con la militancia y la maternidad. La reconstrucción que realiza la autora al indagar otras fuentes, más allá del relato, le permiten sobrepasar lo anecdótico y biográfico. Lo cual es sumamente interesante para pensar cómo se puede utilizar la historia oral sin caer en explicaciones que solo resalten la excepcionalidad del caso estudiado.

Por lo tanto, el libro es una contribución a la historia de las mujeres, principalmente para los estudios de militancia femenina en Argentina. Se destaca el uso de la historia oral como recurso para examinar una problemática que recorre gran parte del siglo XX y que es difícil rescatar en fuentes tradicionales. Sin embargo, a pesar de que es indudable que las transformaciones subjetivas del género femenino resaltan en cada uno de los capítulos -y que no se descuidan las conexiones con el contexto político en el que se insertan los 
relatos- no hay una síntesis que problematice las entrevistas en su conjunto. Al respecto, hubiera sido interesante incluir un apartado a modo de conclusión que remarque los aspectos sobresalientes de todas estas indagaciones y que aglutine los cambios y continuidades de los roles femeninos en esa etapa, complejizando de ese modo la novedad metodológica. 